\title{
NEFROMA QUÍSTICO MULTILOCULAR APORTACIÓN DE 3 NUEVOS CASOS
}

Jorge Subirá Ríos, José Manuel Sánchez Zalabardo, Ángel Elizalde Benito, Joaquín Navarro Gill, José Ignacio Hijazo Conejos, Jesús García-Magariño Alonso, David García Calero, José Antonio López López y José Gabriel Valdivia Uría.

Servicio de Urología. Hospital Clínico Universitario Lozano Blesa. Zaragoza. España.

Resumen.- OBJETIVO: Analizar la forma con la cual se nos presenta el nefroma quístico multilocular y el enfoque diagnóstico- terapéutico que debemos realizar.

MÉTODOS: Aportamos los 3 últimos nuevos casos que se nos han presentado en nuestro servicio en un periodo de 3 años.

RESULTADO: El nefroma quístico multilocular es una lesión benigna, poco frecuente apareciendo en edad adulta, habitualmente de forma asintomática, y en edad infantil frecuentemente como masa palpable. Requiere realizar diagnostico diferencial con tumoraciones malignas.

Jorge Subirá Ríos

Plaza San Francisco 7, 3D

50006 Zaragoza. (España).

kokedoc@hotmail.com

Trabajo recibido: 21 de enero 2008. 
CONCLUSIONES: Se demuestra la gran variedad de presentaciones clínicas, diagnósticos diferenciales y lugares de procedencia de los casos, siendo esto un reflejo de nuestra practica médica diaria sin poder llegar al diagnostico definitivo mediante pruebas de imagen, siendo muy útil la aplicación de la clasificación de Bosniak para indicar la intervención quirúrgica que nos dará el diagnostico definitivo de nefroma quístico multilocular o lo que es más importante, nos descartará proceso maligno.

Palabras clave: Nefroma multilocular quístico. Enfermedad renal quística. Nefrectomía.

Summary.- OBJECTIVE: To analyze the presentation of multilocular cystic nephroma and its diagnostic-therapy scheme.

METHODS: We report the three last new cases presenting in our department in a period of three years.

RESULTS: Multilocular cystic nephroma is a benign lesion, rare that appears both in adult age, generally asymptomatic, and in children, frequently as a palpable mass. Differential diagnosis with malignant tumours is required.

CONCLUSIONS: The great variety of clinical presentations, differential diagnosis and places of origin of the cases is demonstrated, being this a reflection of our daily medical practice, in which we cannot reach definitive diagnosis with imaging tests, being the Bosniak's classification very useful for the setting of indication for surgery, which will give definitive diagnosis of multilocular cystic nephroma or what is more important will rule out malignancy.

Keywords: Multilocular cystic nephroma. Cystic renal disease. Nephrectomy.

\section{INTRODUCCIÓN}

El nefroma quístico multilocular es un tumor renal, poco frecuente, congénito no hereditario y de etiología desconocida $(1,2)$.

Suelen ser unilaterales y únicos formado por múltiples quistes no comunicados entre sí (3). Su presentación más frecuente es en varones menores de 4 años con palpación de masa abdominal. Por encima de los 4 años suelen ser mujeres sin sintomatología asociada $(4,5)$.

Las pruebas por imagen no pueden descartar malignidad precisando tratamiento quirúrgico, para estudio histopatológico de la pieza, incluyendo la nefrectomía parcial-tumorectomía para casos seleccionados (6).

\section{CASO 1}

Niña de 9 años de edad ingresa en el servicio de pediatría procedente de urgencias por segundo episodio de hematuria macroscópica en 20 días.

No presenta antecedentes familiares de interés, antecedentes personales de hemihipertrofia facial por tortícolis congénito, varicela, mononucleosis infecciosa, enúresis nocturna hasta los 7 años, neumonía a los 9 meses y traumatismo en cóccix.

Exploración física: ligera palidez cutánea, peso dentro de percentil $25-50$ y talla percentil 50-75. Sin más hallazgos.

Exámenes complementarios: hemograma, bioquímica, coagulación, urocultivo, función renal, enolasa, alfa feto proteína, radiografía de tórax y ECG normales.

Sedimento urinario: hematuria macroscópica.

Ecografía abdominal: masa de $5 \mathrm{~cm}$ de diámetro en riñón izquierdo, compleja con áreas quísticas/necrosis.

El servicio de pediatría realiza interconsulta a nuestro servicio decidiéndose realizar tras hallazgo ecográfico, una TC abdominal con contraste con el hallazgo de masa dependiente del riñón izquierdo, en cara anterior, de contenido quístico con engrosamientos irregulares endoluminales. Presenta un tabique grueso e irregular de densidad similar a la obtenida en las irregularidades internas descritas. No se observan adenomegalias intercavoaórticas ni periaórticas.

La masa es compatible con tumor de Wilms o adenocarcinoma.

Se decide realización de nefrectomía izquierda: la masa mide $4.5 \mathrm{~cm}$. de diámetro (Figuras 1 y 2).

El diagnóstico anatomopatológico es de nefroma mesoblástico quístico (quiste renal multilocular).

\section{CASO 2}

Mujer de 43 años de edad, ama de casa, alérgica al contraste yodado y fumadora de 1 paquete diario de cigarrillos, histerectomizada y ooferectomizada derecha por endometriosis.

La paciente se encuentra en estudio por el Servicio de Hematología por leucocitosis aislada; se le realizó ecografía abdominal hallando un riñón izquierdo desestructurado con imágenes quísticas o hidronefrosis y siendo remitida a nuestras consultas.

En el interrogatorio refiere un ingreso de 27 días de duración, cuando tenía 12 años, en otro hospital por 
dolor lumbar con hematuria sin conocer su diagnóstico. También refiere ocasionales dolores lumbares de tipo mecánico con astenia moderada.

\section{Exploración física: sin hallazgos}

Pruebas complementarias: hemograma con ligera leucocitosis sin desviación de fórmula leucocitaria siendo el resto normal, bioquímica y coagulación normales.

Renograma MAG-3-Tc-99m: riñón derecho normal. Captación heterogénea en riñón izquierdo con dilatación calicilar superior, retención en polo superior izquierdo presentando un enlentecimiento excretor de la curva cuya actividad desaparece en imágenes tardías.

TC sin contraste: masa quística renal polar superior izquierda de aproximadamente $12 \mathrm{~cm}$. de diámetro máximo desplazando páncreas y bazo. Internamente constituida por múltiples quistes de diferentes tamaños y presenta tabiques internos heterogéneos, alguno de ellos grueso e irregular sugestivo de nefroma quístico multinodular o carcinoma de células renales quístico.

Se decide realizar nefrectomía con linfadenectomía izquierda. En el estudio anatomopatológico de la pieza se informa como riñón que presenta tumoración de $9 \times 10 \mathrm{~cm}$. multiquística que ocupa la mayor parte del riñón (Figura 3). El contenido del quiste es ambarino sin presencia de partes sólidas ni adherencia del tumor en la cápsula. Las cavidades están revestidas de un epitelio

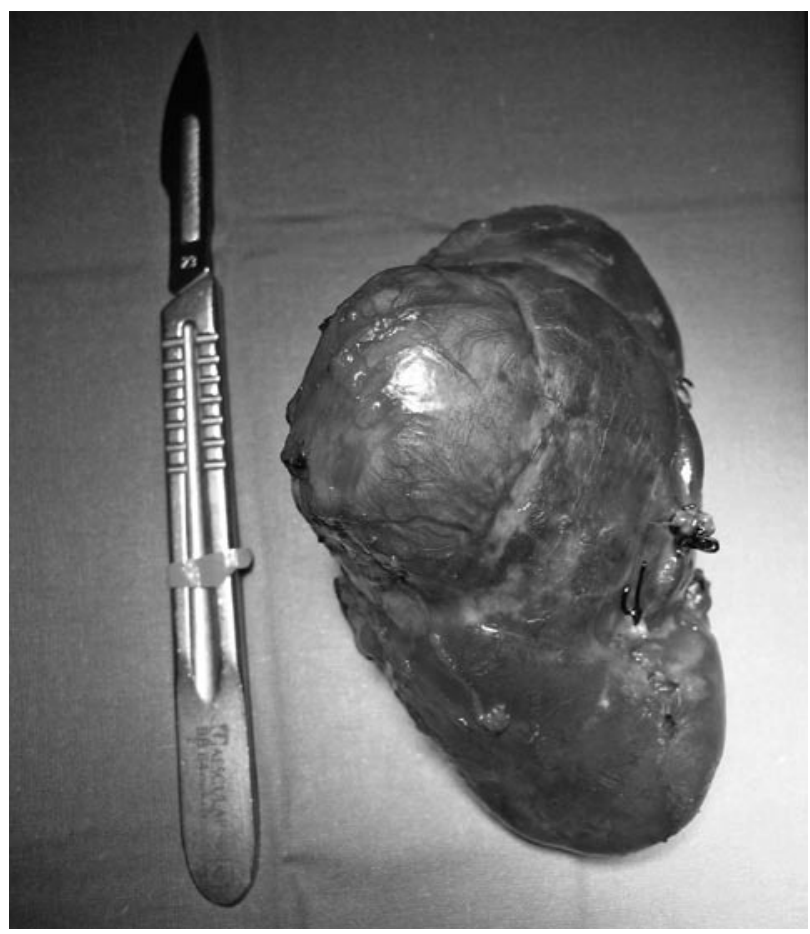

FIGURA 1. Pieza de nefrectomía izquierda. simple con presencia de frecuentes células con morfología en "tachuela". El estroma intercelular es fibroso. Lesión bien delimitada del parénquima renal conservado. Diagnóstico anatomopatológico de fumor quístico multilocular benigno de riñón (Figura 4).

\section{CASO 3}

Mujer de 57 años de edad, antecedentes personales de depresión, en tratamiento médico, intervenida de varices.

En estudio por su médico de atención primaria por lumbalgia de 1 año de evolución, en tratamiento médico con AINES. Se realizó ecografía abdominal encontrándose quiste de tipo mixto (sólido y líquido) en riñón derecho de $7,4 \times 4,2 \mathrm{~cm}$. de diámetro con sospecha de quiste hidatídico.

La paciente es remitida a nuestras consultas. La exploración es anodina y las pruebas de laboratorio incluyendo serología de hidatidosis, resultan normales.

Se solicita TC abdominal para completar el estudio encontrándose tumoración en región interpolar y polar superior derecha de contorno bien delimitado, tabicación interna y baja densidad de contenido que presenta un tamaño de $70 \times 45 \times 40 \mathrm{~mm}$ correspondiente a quiste complejo no se aprecian adenopatías regionales (Figura 5). Las características de la tumoración quística no permiten descartar totalmente malignidad.

Se procede a realizar nefrectomía derecha y estudio anatomopatológico de la pieza informando de: formación quística de $4^{\prime} 5 \mathrm{~cm}$. multiloculada y contenido seroso, bien delimitada y revestida de epitelio plano, con diagnóstico de nefroma multiquístico.

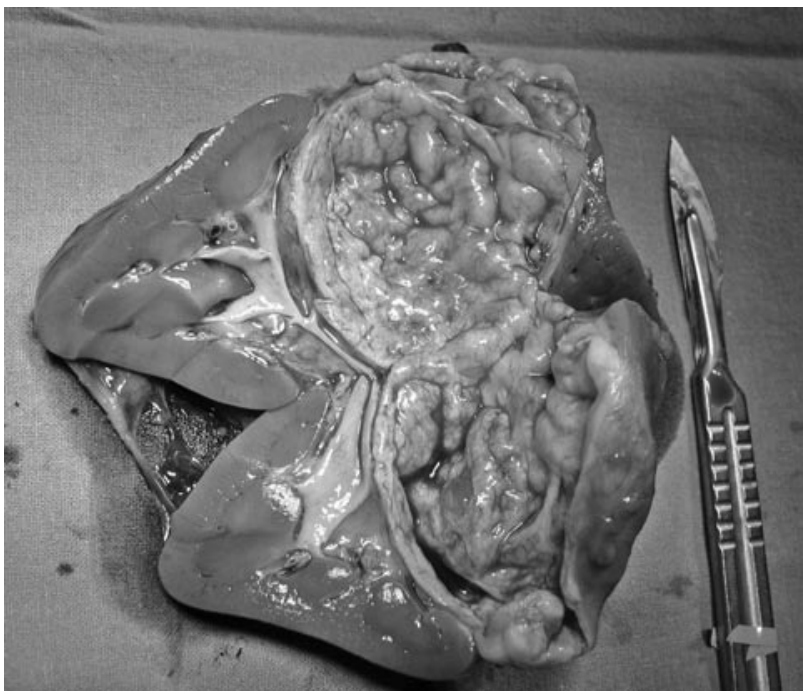

FIGURA 2. Apertura de pieza de nefrectomía. 


\section{DISCUSIÓN}

El Nefroma Quístico Multilocular (NQM) es una lesión poco frecuente, congénita y no hereditaria $(1,2)$ de causa desconocida y preferentemente unilateral y único (3). Ha sido designada bajo diversas denominaciones desde que en 1892 fuera descrita por Edmunds como adenoma quístico. Entre estas denominaciones se encuentran el hamartoma quístico, nefroma quístico benigno, tumor de Perlman (6).

Tiene 2 grupos de edad de presentación opuestos en sexo: en el $73 \%$ de los casos es en pacientes menores de 4 años preferentemente varones y siendo la masa palpable su manifestación clínica inicial. En pacientes mayores de 4 años el $89 \%$ son mujeres habiendo 2 picos entre 4-20 años y entre 40- 60 años. En adultos suele aparecer el tumor como hallazgo casual $(4,5)$.

Las pruebas de imagen no son capaces de llegar a su diagnóstico, planteando el diagnóstico diferencial en edad pediátrica con un espectro de lesiones que van en un extremo desde un quiste multilocular benigno, un quiste multilocular con tumor de Wilms o quiste multilocular con nódulos tumorales de Wilms hasta la forma quística del tumor de Wilms; y en la edad adulta con la variedad quística del carcinoma de células renales (6).

En la urografía excretora se puede llegar a demostrar, con frecuencia, proyección de la masa en la pelvis renal (7).

La ecografía nos hablará de masa renal con múltiples espacios quísticos no comunicados entre sí, separados por tabiques fibrosos de estroma.

TC y RMN abdominal demostrarán una masa renal multiloculada; Los tabiques suelen ser delgados sin realzar

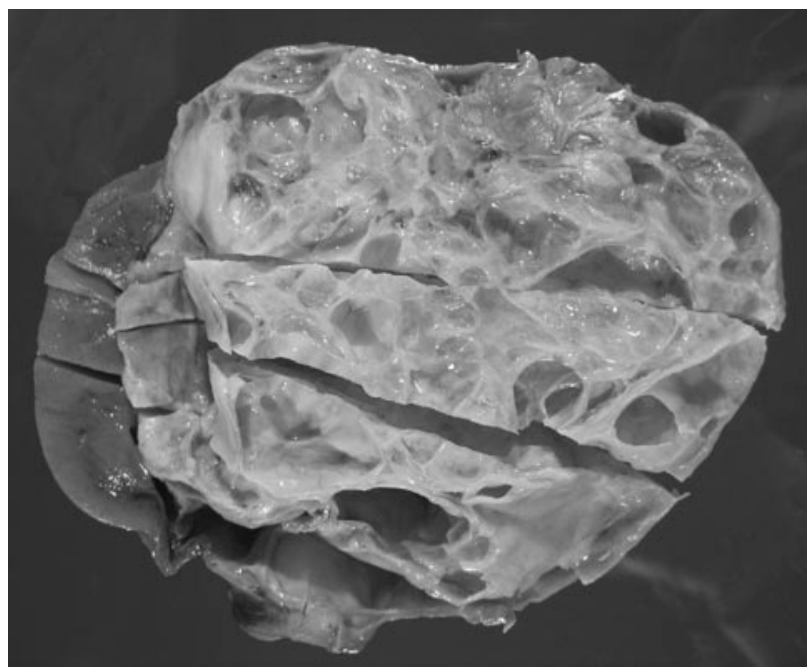

FIGURA 3. Tumoración multiquística que ocupa la mayor parte del riñón. con el contraste (4). La presencia de hemorragia y de necrosis es rara. Las calcificaciones son raras siendo mas frecuentes en los pacientes pediátricos $(10 \%)$.

En angiografía aparece lesión hipovascular pero el grado de vascularización depende del tamaño del quiste y de la cantidad de estroma que contenga.

La PAAF no estaría indicada ya que los quistes no están comunicados entre si por lo que requeriríamos puncionar todos ellos.

Sin llegar a su diagnóstico si que se puede concluir que se trata de un quiste complejo según la clasificación de Bosniak lo que nos obligaría a tratarlo realizando intervención quirúrgica: nefrectomía, nefrectomía parcial, tumorectomía (6). El estudio histológico de la pieza nos descartará malignidad y nos decantará finalmente por esta patología benigna (6).

El criterio patológico propuesto por Powel incluye: lesión unilateral, única y multilocular; quistes con revestimiento epitelial no comunicados entre si ni con la pelvis renal; el resto del riñón, si esta presente, es normal; inexistencia de elementos renales dentro del quiste. Las calcificaciones, cuando están presentes, siguen patrón inespecífico (central o periférico).

\section{CONCLUSIÓN}

No hay prueba de imagen que nos diagnostique con certeza esta lesión y lo que es mas importante que nos descarte proceso maligno puesto que el único diagnostico de certeza es mediante estudio histológico de la pieza.

En nuestros 3 casos que presentamos, diagnosticados entre 2004 y 2007 , se demuestra la gran variedad de

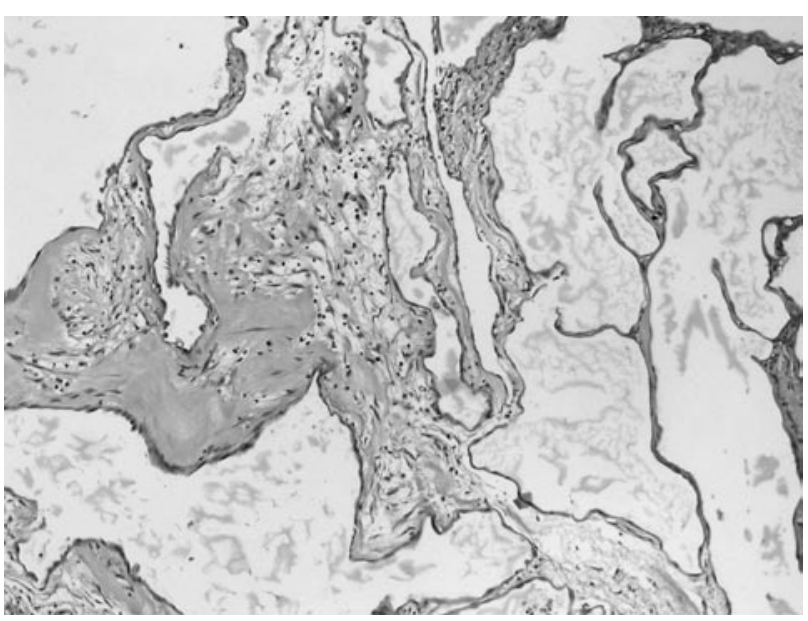

FIGURA 4. Estudio histológico de la pieza con hallazgo de células en "tachuela". 


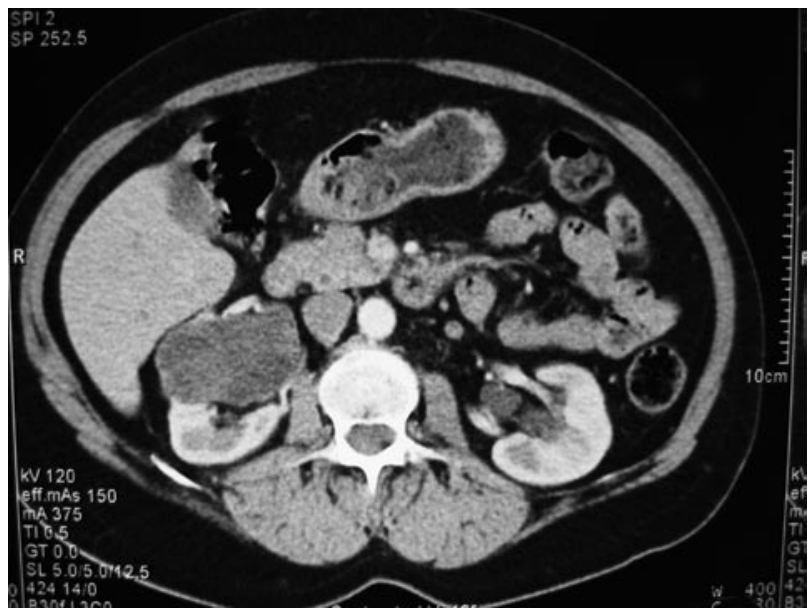

FIGURA 5. TC con contraste IV con hallazgo de quiste complejo.

presentaciones clínicas, diagnósticos diferenciales y lugares de procedencia de los casos, siendo esto un reflejo de nuestra práctica médica diaria.

En todos los casos se indicó intervención quirúrgica por la existencia de duda razonable de proceso maligno aplicando la clasificación de Bosniak y en todos ellos se trató de un nefroma quístito multilocular benigno sin elementos inmaduros $u$ otros que indicasen potencial maligno.

\section{BIBLIOGRAFÍA y LECTURAS \\ RECOMENDADAS (*lectura de interés $y^{* *}$ lectura fundamental)}

**1. Madewell JE, Goldman SM, Davis CJ et al. Multilocular cysticnephroma: a radiographic-pathologic correlation of 58 patients. Radiology 1983; 2:309-21.

2. Robben, A et al. Multilocular cystic nephroma. Journal Belgeum Radiology 1998; 5:247.

3. Rumack WC: Diagnóstico por ecografía 1999; 2:37072.

*4. Herráiz del Olmo F, Merino Sánchez C, Sánchez Díaz E et al: Nefroma quístico multilocular: diagnóstico mediante técnicas de imagen. Arch. Esp. de Urol 2004; 57:745-48.

5. Kural A R et al. Multilocular cystic nephroma: an usual Localization". Urology 1998; 52:897-99.

**6. Morga Egea JP, Fontana Compiano LO, Martínez F et al. Nefroma quístico multiloculado. Un reto diagnostico y terapéutico, a proposito de dos casos. Arch. Esp. de Urol 2004; 57:431-34.

**7. Rebassa LLull MJ, Muñoz Vélez D, Hidalgo Pardo F et al. Nefroma quístico. A proposito de 5 casos. Arch. Esp. de Urol 2000; 53:476-79. 